\title{
DESENVOLVIMENTO DE UM JOGO EDUCACIONAL PARA ELUCIDAR A APLICAÇÃO DE ENGENHARIA DE MÉTODOS EM UMA ATIVIDADE DE \\ PICKING
}

\author{
Júlio Cesar Vasconcelos Conserva (UFCG/CDSA) julio.conserva@outlook.com \\ Lucas da Silva Almeida (UFCG/CDSA) lucameid@gmail.com \\ Yan Rink Aguiar Feitoza (UFCG/CDSA) yanrink08@gmail.com \\ João Pedro Marques Sousa (UFCG/CDSA) pedro321joao@ hotmail.com \\ Marcelo da Silva Ribeiro Rodrigues (UFCG/CDSA) marcelo.srrod@gmail.com
}

\section{Resumo}

Com a identificação da dificuldade de alunos de engenharia em aplicar de forma pratica seus conhecimentos adquirido durante sua formação sobre ferramentas e métodos que podem ser importantes na sua vida profissional, o presente artigo tem o intuito de elucidar a partir de um jogo didático a aplicação prática da Engenharia de Métodos em logística, no ambiente acadêmico, de modo que seja possível simular a dinâmica de picking de diversos produtos através de diferentes métodos, de forma que possa ser utilizado para desenvolver habilidades de tomada de decisão e incentivar o desenvolvimento de métodos melhorados, podendo desta forma, ser utilizada para disciplina de engenharia de métodos, por utilizar seus princípios de tempos e movimentos.

Palavras-Chaves: (Educação, Engenharia de Métodos, Logística, Jogos, Layout).

\section{Introdução}

O mercado de trabalho tem se tornado cada vez mais exigente, fazendo com que os alunos de engenharia busquem um diferencial que os credencie a ter espaço no mercado. Um dos problemas mais comuns para alunos recém-formados é a falta de experiência para resolver problemas reais, aplicando as ferramentas que lhes foram passadas na academia.

De acordo com Colenci (2000), desde algum tempo, a preocupação com o ensino, e especificadamente com o ensino da engenharia, vem aumentando no meio acadêmico. Isso ocorre porque ao se formar e ingressar no mercado de trabalho, o profissional 
precisar ser treinado para compatibilizar a realidade em diferentes níveis de interpretação.

A partir disso, a busca por novas metodologias de ensino tem aumentado cada vez mais em escolas e universidades em decorrência do baixo aproveitamento dos alunos em aulas puramente teóricas, os jogos educativos surgem como meio de auxiliar o entendimento da teoria aplicando práticas simples e dinâmicas.

Os jogos podem ser ferramentas instrucionais eficientes, pois eles divertem enquanto motivam, facilitam o aprendizado e aumentam a capacidade de retenção do que foi ensinado, exercitando as funções mentais e intelectuais do jogador (TAROUCO et al., 2004).

Assim sendo, para Júnior e Farias (2016), o jogo educativo é uma atividade lúdica que oferece para o professor uma oportunidade de continuar trabalhando e reforçando o conteúdo e com relação ao aluno, promove uma participação mais efetiva, buscando sempre um melhor desempenho.

O presente estudo tem como objetivo criar um jogo que proporcione de forma prática o entendimento sobre como a engenharia de métodos pode atuar junto da logística, melhorando o desempenho da atividade em virtude do método utilizado, levando para o jogador uma experiência próxima à realidade e a assimilação de melhoria continua do método.

\section{Referencial Teórico}

\subsection{Engenharia de métodos}

A Engenharia de Métodos, inserida no estudo de projetos, operações e melhoria de sistemas produtivos da entrega de bens e serviços, possui sua história estreitamente associada ao surgimento da Engenharia de Produção em decorrência da relevância e pioneirismo das proposições e contribuições de Frederick W. Taylor, Frank B. Gilbreth e Lillian M. Gilbreth, sendo estes reconhecidos como exercendo papéis fundamentais na origem do tratamento adequado e sistemático dos processos de produção (DURAN; CETINDERE; AKSU, 2015; MENDOZA-CHACÓN et al., 2016). 
Para Barnes (1977), o propósito da engenharia de métodos é o "estudo sistemático dos sistemas de trabalho com os seguintes objetivos: desenvolver o sistema e o método preferido; padronizar esse sistema e método; determinar o tempo gasto por uma pessoa qualificada e trinada num ritmo normal; e orientar o treinamento do trabalhador no método preferido".

Barnes (1977) salienta que o custo da aplicação do estudo dos tempos e movimentos sempre levará em conta o retorno do capital almejado. A operação será desenvolvida até o ponto em que depender de potenciais benefícios. Se necessário, estabelecem-se tempos-padrão para uma determinada operação e utilizada como base para incentivos salariais.

Quatro fatores determinam a combinação de técnicas no estudo de tempos e movimentos: o conteúdo da tarefa; a vida prevista; considerações relativas à mão de obra; e investimento de capital em construções.

\subsection{Logística}

Para Paura (2012), a logística estuda como prover a lucratividade nos serviços de distribuição ao cliente, no fluxo de materiais da empresa, no planejamento da compra, planejamento de produção e controle de transportes. Na empresa a logística aparece como organizadora do fluxo de produtos e serviços.

Segundo Ballou, (1999) a logística é o processo de planejamento do fluxo de materiais, objetivando a entrega das necessidades na qualidade desejada no tempo certo, otimizando recursos e aumentando a qualidade nos serviços.

\subsection{Picking}

Rodrigues (2007) salienta que picking é a atividade correta de coleta do mix de produtos para atendimento do consumidor final.

O processo de separação de pedidos é comumente o mais difícil e, desta maneira, tem um elevado impacto no custo do armazém, de $30 \%$ a $40 \%$ dos custos com mão-de-obra na armazenagem estão associados a essa atividade (SOUZA, 2008; MEDEIROS, 1999).

A atividade de picking reduz o tempo de separação dos pedidos, aumenta a produtividade e aprimora o tempo de atendimento desses mesmos pedidos, o que 
ocasiona em enorme vantagem da empresa frente aos seus concorrentes. (GONTIJO, 2012).

\subsection{Jogos empresariais}

Segundo Feldmann et al. (2016), os jogos empresariais servem como simuladores para o desenvolvimento e aprendizagem de ferramentas ou processos. Alguns aspectos são analisados quanto à aprendizagem e tomado de decisão. Tais ferramentas funcionam recriando circunstancias que permitem aos pesquisadores a coleta de dados quanto ao fenômeno analisado.

Goldschmidt (1977) salienta que o jogo empresarial simulado é um exercício sequencial de tomada de decisões, estruturado dentro de um modelo de conhecimento empresarial, em que os participantes assumem o papel de administradores de empresas.

Para Gramigna (1994), os jogos possuem quatro características: a primeira sobre as possibilidades de simular a realidade das empresas, onde as atividades devem ser semelhantes às vivências do participante; a segunda refere-se à definição de papéis, onde o comportamento do participante é determinado de acordo com o tipo que exerce; a terceira trata das regras do jogo, onde o facilitador deve apresentar claramente as regras; e a quarta característica que trata das condições para que o jogo seja atrativo e envolvente, onde o facilitador deve entusiasmar o grupo antes de começar o jogo.

\section{Metodologia}

A pesquisa a seguir é classificada como exploratório-descritiva e explicativa. Isto se deve ao levantamento bibliográfico feito, em métodos pedagógicos para jogos educacionais e artigos de outros jogos similares.

Para o levantamento bibliográfico, foram utilizados sites de busca como Scielo, Google Acadêmico, ABNT, entre outros. Os critérios para incluir dados destes sites foram: ano de publicação dos artigos, sites de Revistas Especializadas, artigos sobre jogos educativos e concepção de ideias para desenvolver um jogo colaborativo no âmbito acadêmico. 
Foram realizados testes deste mesmo jogo, onde foi possível observar o entendimento do jogo quanto às regras, métodos a utilizar e a compreensão de eficiência e melhoria ao decorrer das rodadas.

Para evidenciar a melhora nos resultados a partir do andamento das rodadas no jogo, realizou-se ainda cronometragens com o uso de smartphones para comparativo dos resultados obtidos antes e depois das melhorias aplicadas pelos jogadores.

\subsection{Confecções dos materiais}

A confecção dos caixotes foi feita com os palitos de madeira, devidamente aparados e aderidos com cola quente; da mesma maneira assim foram elaborados os pallets. $\mathrm{O}$ cartão de comanda, manual e cartão de layout foram feitos em software de edição vetorial e impressos. Fichas grandes, pequenas e caixotes de plástico foram reaproveitados de um jogo de tabuleiro.

A aplicação do jogo deve-se a observação das aulas de Engenharia de Métodos, ministradas pelo professor Dr. Daniel Augusto Moura, onde se analisou o conteúdo das mesmas bem como possíveis aplicações.

\section{Resultados}

\subsection{Especificações do produto}

Os seguintes componentes fazem parte do jogo:

a) 1 cartão de layout: Cartão que irá mostrar a disposição das prateleiras, a entrada e a saída na superfície.

Figura 01 - Cartão de layout 


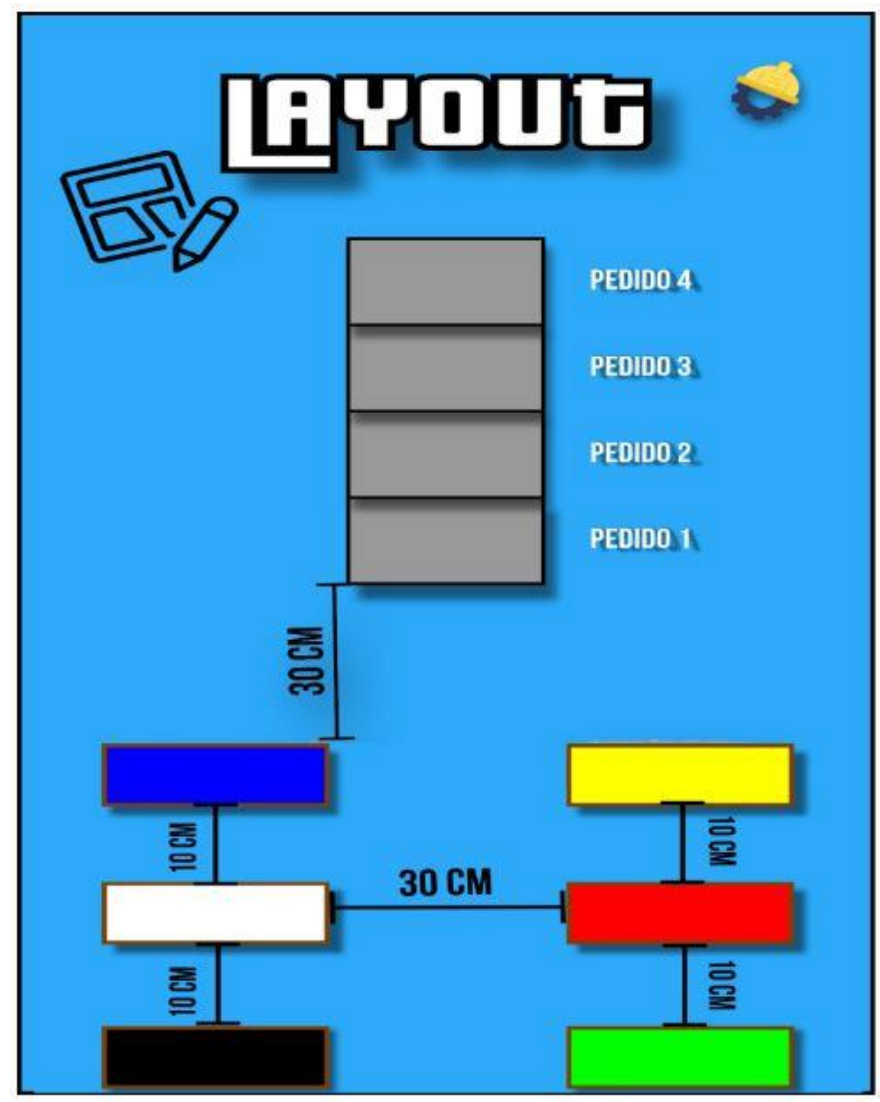

Fonte: Autor (2019)

b) 6 Prateleiras de madeira: Prateleiras com formato de paralelepípedo, que possuem dimensões de $5 \mathrm{~cm}$ de largura, $2 \mathrm{~cm}$ de altura e $12 \mathrm{~cm}$ de comprimento. Elas representam as prateleiras onde ficarão dispostos os produtos.

Figura 02 - Prateleira de madeira

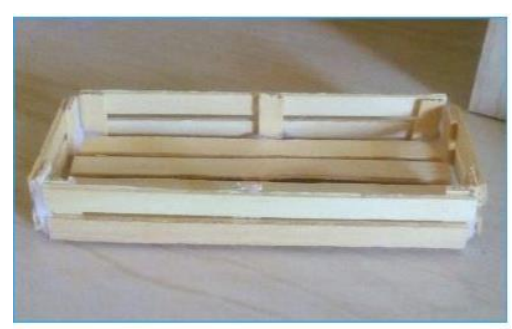

Fonte: Autor (2019)

c) 16 caixotes de madeira: Caixotes com formato de paralelepípedo, com dimensões de $4 \mathrm{~cm}$ de largura, $3 \mathrm{~cm}$ de altura e $7 \mathrm{~cm}$ de comprimento. Eles representam os caixotes onde pode se deslocar os produtos. 


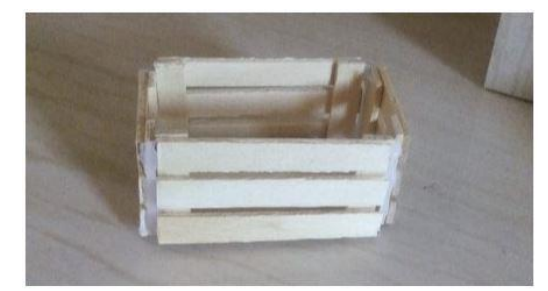

Fonte: Autor (2019)

d) 3 pallets de madeira: Pallets com formato retangular com lados de medidas iguais de $12 \mathrm{~cm}$ e altura de $0,8 \mathrm{~cm}$. Eles representam os pallets onde podem ser carregados múltiplos caixotes.

Figura 04 - Pallet de madeira

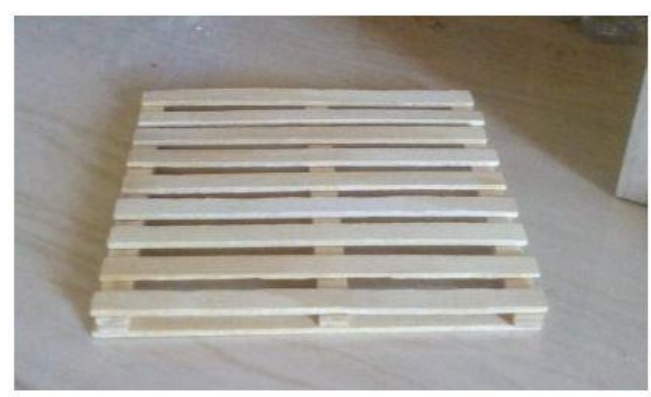

Fonte: Autor (2019)

e) 48 fichas grandes de plástico: Fichas com formato cilíndrico de raio $0,7 \mathrm{~cm} \mathrm{e}$ altura 0,6 cm, sendo 8 de cada cor (vermelho, amarelo, azul, branco, verde e preto). Elas representam tipos de produto do centro de distribuição.

Figura 05 - Fichas grandes

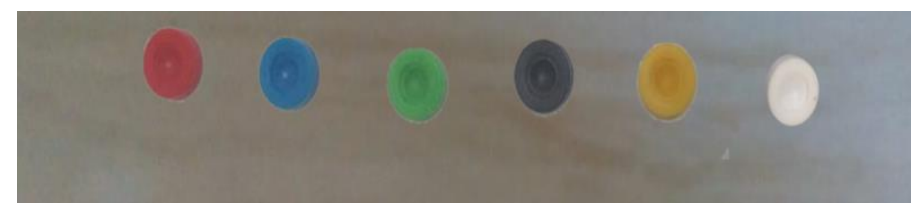

Fonte: Autor (2019)

f) 450 fichas pequenas de plástico: Fichas com formato cilíndrico de raio $0,55 \mathrm{~cm}$ e altura 0,5 cm, sendo 75 de cada cor (vermelho, amarelo, azul, branco, verde e preto). Elas representam tipos de produto do centro de distribuição.

Figura 06 - Fichas pequenas 


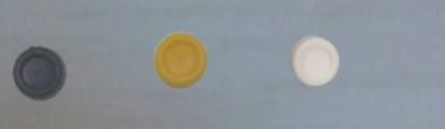

Fonte: Autor (2019)

g) 6 Caixas de plástico com tampa: Caixas no formato de paralelepípedo onde são guardadas as fichas. Não atuam no jogo.

Figura 07 - Caixas de plástico

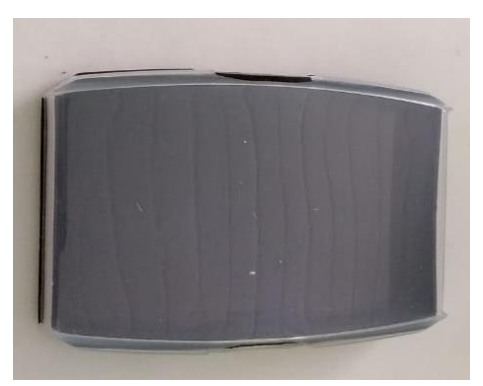

Fonte: Autor (2019)

h) 1 Cartão de comandas: Cartão que irá mostrar as demandas a serem atendidas pelo jogador. 


\section{manuil prexmg 마묘}

\section{- COMPONFMTES}

- 1 Cartāo Layout

- 1 Manual do jogo

1 Conjunto de fichas

- 16 Caixotes de madeira

- 6 prateleiras

- 3 Pallets

- 1 Cartão de comandas

\section{- aszino}

Entregar todos os pedidos solicitados com o menor tempo e menor quantidade de movimentos possiveis ao término de todas as rodadas

\subsection{0}

- O jogador deverá transportar os produtos pelo solo. de onde estăo armazenados até a área destinada para expedicăo.

- Em caso de queda do produto durante o transporte ele será considerado avariado e por exigências do setor de qualidade ná poderäo ser entregues aos clientes sendo necessário que se pegue outro produto para substitui-to.

- Na primeira rodada o jogador deverá realizar o picking e a expedicāo dos pedidos transportando os produtos um por vez, sequindo as marcacōes dos caminhos apresentados a seguir:

\section{- preparacio}

- OE jogadorea devem se dividir em equipos Apda essa divisaio o orupe deverá designar quem fará o papel do trabilhador que irh realizar o picking e enviar os produtos para expedigdo. Oe demais membros da equipe auxiliaram ha cronometragem do tempo, contagem de movimentos e auxiliaram nas esoolhas durante o decorrer do jogo.

Cada equipe deverd organizar o layout a seguir, respeitando a ordern dos produtos da maneira em que estáo dispostos:

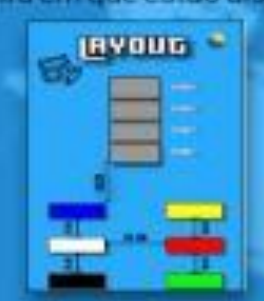

Cacla equipe recebe a comand contendo os pedidon

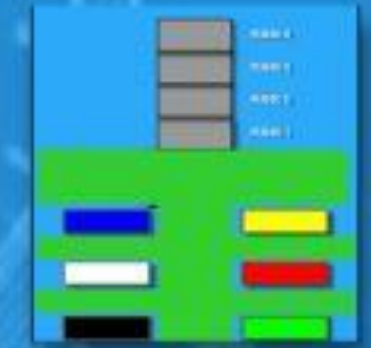

- Ao termino de cada rodada a equipe deve analisar o tempo de execuçáo dos pedidos e discutir sobre a implementaça de melhorias que venham a tempo.

- Serăo permitidas a realizaça de uma melhoria ao termino de cada rodada.

- Os principios de utilização de cada melhoria estāo dispostos a seguir. acarretar na diminuicäo do

Fonte: Autor (2019)

i) Manual do jogo - Ficha técnica onde se explica regras, objetivo e funcionalidade do jogo. 
Figura 09 - Manual página 1

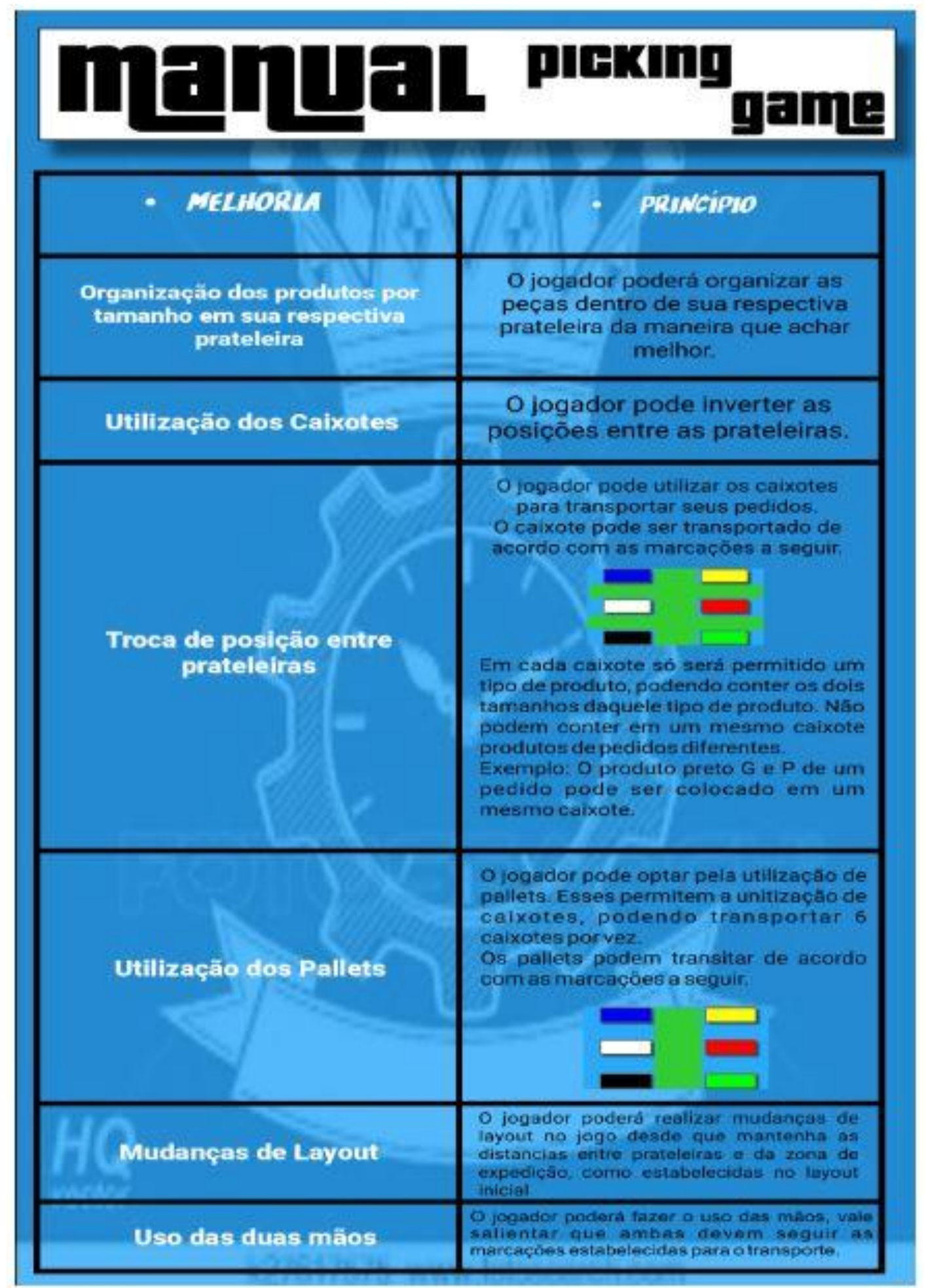

Fonte: Autor (2019) 
Figura 10 - Manual página 2

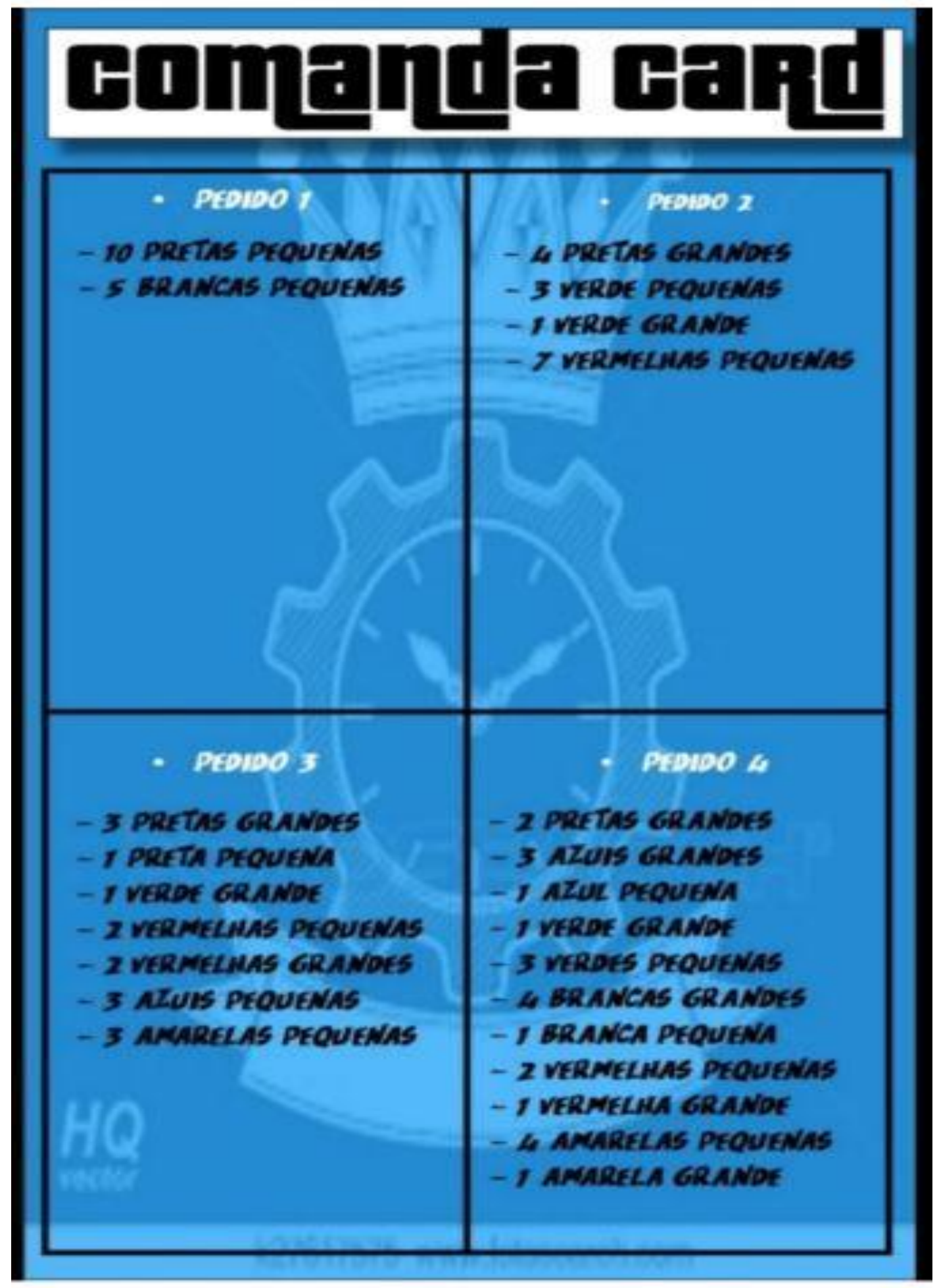

Fonte: Autor (2019) 


\subsection{Custos}

Tabela 01 - Custos de produção do jogo

\begin{tabular}{cccc}
\hline Nome & Quantidade & $\begin{array}{c}\text { Valor } \\
\text { (unidade) }\end{array}$ & Valor total \\
\hline $\begin{array}{c}\text { Cartão de layout } \\
\text { Pacotes de palitos de } \\
\text { madeira }\end{array}$ & 1 & $\mathrm{R} \$ 1,50$ & $\mathrm{R} \$ 1,50$ \\
Cola branca & 2 & $\mathrm{R} \$ 2,00$ & $\mathrm{R} \$ 4,00$ \\
Bastão de cola quente & 3 & $\mathrm{R} \$ 3,50$ & $\mathrm{R} \$ 3,50$ \\
Conjunto de fichas & 1 & $\mathrm{R} \$ 0,50$ & $\mathrm{R} \$ 1,50$ \\
Manual do jogo & 1 & $\mathrm{R} \$ 35,00$ & $\mathrm{R} \$ 35,00$ \\
\end{tabular}

Fonte: Autor (2019)

\subsection{Escolha dos materiais}

A escolha do material foi feita de forma que tivesse um baixo custo e trouxesse para o jogador uma experiência próxima à realidade de forma que simulasse o cenário que é proposto no jogo, foram escolhidos palitos de picolé para fazer os caixotes, pallets e as prateleiras, o uso da cola branca e cola quente foram importantes para deixas às peças firmes, assim podendo ser utilizado sem medo de danificar, por fim utilizamos peças cilíndricas de cores e tamanhos variados para simular produtos diferentes.

\subsection{Teste do Picking Game}

Após a construção do jogo realizou-se a aplicação pratica do mesmo, onde ao fim de diversas rodadas de experimento de aplicação de melhorias obteve-se os seguintes resultados: 


\begin{tabular}{ll}
\hline Rodada & Resultado \\
\hline Inicial & $6 \min 23 \mathrm{~s}$ \\
Final & $3 \min 42 \mathrm{~s}$ \\
\hline \multicolumn{2}{c}{ Fonte: Autor (2019) }
\end{tabular}

Ao analisar os resultados obtidos pode-se observar uma diminuição de 2 min 41s no tempo de execução da atividade ilustrada no jogo, o que evidencia um grande ganho de produtividade.

\section{Considerações finais}

Tendo em vista a situação geral apresentada previamente, e das conveniências que a utilização da metodologia baseada em jogos pode proporcionar, a concepção deste jogo agrega valor diretamente a aprendizagem dos assuntos abordados.

Com os testes realizados pode-se comprovar que o principal objetivo jogo foi atingido, proporcionando uma melhoria de $42,1 \%$ no tempo de execução da atividade proposta, a partir da aplicação pelos jogadores de seus conhecimentos. Vale salientar que o jogo pode ainda permitir a obtenção de resultados ainda melhores do que os conquistados nos testes, pois a aplicação das melhorias se dá de forma subjetiva de acordo com a vontade e percepção do jogador.

Assim sendo, pode-se concluir que a experiência oferecida pelo jogo auxilia exponencialmente na aprendizagem dos princípios da engenharia de métodos aplicada a ambientes logísticos, além de contribuir para desenvolvimento de analise de problemáticas e tomadas de decisão através da sistemática de rodadas do jogo, pressionando o melhoramento continuo do método de expedição e organização do layout.

\section{Referências}

BARNES, R. M. Estudo de tempos e movimentos: projeto e medida do trabalho.6.a ed. São Paulo, 1977. 
ACADÊMICA. 2000. Disponível em: <https://teses.usp.br/teses/disponiveis/18/18140/tde-14052004150657/publico/Dissertacao_Ana_Teresa_Colenci2.pdf>. Acesso em: 02 dez. 2019.

FELDMANN, P.R. et al. Jogos de Empresas: Abordagens ao fenômeno, Perspectivas Teóricas e Metodológicas. Rio de Janeiro, Jan/Fev 2017. Disponível em: <http://www.scielo.br/pdf/rac/v21n1/14156555-rac-21-01-00019.pdf>. Acesso em: 02 Dez. 2019.

PAURA, G.L. Fundamentos da Logística. Curitiba, 2012. Disponível em:

<http://redeetec.mec.gov.br/images/stories/pdf/proeja/fundamentos_logistica.pdf $>$. Acesso em: 02 Dez. 2019.

PORTELLA, G.A. et al. Métodos de organização da atividade de picking na gestão logística: um estudo de caso no centro de distribuição de uma rede de supermercadista do Rio Grande do Sul. Rio Grande do Sul, Outubro, 2013. Disponível em:

〈http://www.abepro.org.br/biblioteca/enegep2013_tn_sto_177_009_23132.pdf>. Acesso em: 02 Dez. 2019.

TAROUCO, Liane Margarida Rockenbach et al. Jogos educacionais. 2004. Disponível em: <https://seer.ufrgs.br/renote/article/view/13719/8049>. Acesso em: 30 nov. 2019.

TOZI, L.A. et al. Análise de estratégias de picking aplicada a armazém de empresas de autopeças por meio de simulação discreta. Disponível em:

<https://www.aedb.br/seget/arquivos/artigos15/22222338.pdf>. Acesso em: 02 Dez. 2019. 